\title{
Gestão pública: fluxo e refluxo
}

\author{
PEDRO SCURONETO
}

A

GERAÇÃO QUE atingiu sua maturidade política na década de sessenta chega finalmente ao poder em um contexto de inovação e reforma semeca os problemas as ca os problemas e as mudanças tinham pouco a ver com contradiçóes de natureza filosófica ou ideologia, porém muito em relação a formas e meios de alcançar objetivos comuns. O Estado afirmou-se na determinação do sistema político e agiu de forma virtualmente autônoma, como se fosse o arquiteto da ordem económica e social. Hoje, contudo, em pleno refluxo de uma crise que abalou profundamente a gestão pública, as mudanças se impóem com rapidez, consolidam-se e nos obrigam a compreender o ciclo emergente não como uma nopa ordem ou mais uma fase do destino, porém como algo em movimento, uma experiência que requer observação direta e participação.

A perspectiva é de desalinhamento e não de realinhamento de forças (Schelesinger, 1992:39), acarretando, entre outras coisas, o debilitamento do processo político visto como resultado das pressóes de interesses em conflito e de arranjos obtidos a partir dessas mesmas pressōes, para as quais o sistema político não é mais que um recipiente passivo. Sujeito a esse tipo de intervenção, legítima porque as políticas são formadas justamente para realçar interesses, o Estado limita-se a definir e encaminhar segundo critérios corporativistas puros ou adaptados a objetivos de camaras setoriais.

Após uma sucessão de mudanças, todavia, a análise volta-se mais uma vez para o sistema político considerado como ação de toda a sociedade, concentra-se na gestão pública vista à luz de suas funçōes de output, em escolhas que requerem alocação imperativa de valor e estruturas singulares de tomada de decisão na base de colaboração politicamente consentida (Scuro Neto, 1989a:206). Assim, a representação do processo político como uma configuração de interesses não é mais tão relevante quanto a reavaliação afirmativa dos mecanismos institucionais e dos procedimentos que levam à formação de políticas públicas.

Ironicamente isso só pôde ocorrer à medida que o Estado foi mostrando sinais de esgotamento e ineficiência cada vez maior na redução de conflitos e na 
promoção de consenso e justiça social. Problemas institucionais do tipo que os EUA enfrentaram na década de 60 (envolvimento militar no Vietnã, conflitos raciais, movimento estudantil, caso Watergate), seguidos de crise fiscal, altas taxas de juros, inflação e recessão nos anos setenta, deram motivo ao antiestatismo e oportunidade à recherche du temps perdu que os conservadores utilizaram para retornar ao poder pregando a minimalização do governo.

Anos depois, os mesmos ciclos e problemas reproduziam-se no Brasil, porém, sem impedir a aplicação da abordagem pluralista a fenômenos institucionais extremamente diversos e que o sistema político continuasse a ser encarado como um jogo de soma zero no qual existem quantidades fixas de poder, ganhos para uns e perdas para outros (Lipset, 1992:104). Isso não foi só obra do atraso ou efeito da distância com relação ao epicentro das mudanças internacionais. De um lado, o aparato institucional corporativista permaneceu virtualmente intacto e a sociedade civil organizada ainda está imersa na aquisição de direitos e criação de privilégios. De outro, apesar de, teoricamente, grupos de interesse não desfrutarem de situação definida no sistema político (têm poder mas não autoridade), entre nós sua atuação parece desmentir a tendência geral, associando-se, como as jatis indianas, à inércia social alimentada pelo círculo vicioso do inter-relacionamento e causação cumulativa. (Myrdal, 1971:109, 442-443)

Por conta desses desvios, a análise da crise da gestão pública no Brasil ainda dá ênfase aos quadros do funcionalismo público e acentua a importância de sua distribuição e qualificação profissional. Identifica ilbas de excelência (Tafner \& Nascimento, 1994) e até mesmo vanguardas, atores principais (Ipea-Ibam-Enap, 1994) que irão conduzir a reforma administrativa e abrir caminho para uma sociedade sem privilégios ou discriminaçáo (Anderson, 1986). Menciona pactos, minipactos e a reformulação espacial de núcleos e fluxos de poder, que levam gradual e silenciosamente à descentralização política para todos os efeitos, superior ao poder centralizado. Há quem chegue mesmo a propor o abandono dos grandes programas ou planos globais em favor da constituiçăo de microprojetos políticos de desenvolvimento (Poggiese \& Francioni 1994).

Dessa forma, ao passo que no mundo industrializado a reforma administrativa é avaliada em termos dos vínculos entre a eficácia do setor público e o desempenho do conjunto da economia, no Brasil, da mesma forma que em outros países do Terceiro Mundo, o jogo político ainda é o que importa. Em nome dessa preferência nacional (condicionada em parte pela natureza dos recursos de apoio à pesquisa científica e em larga margem pela dimensão do campo que define tal preferência) isola-se a gestão pública do gerenciamento do resto da economia, simplifica-se as experiências estrangeiras e acentua-se a necessidade de ruptura. Ignora-se a natureza cíclica e o caráter inovador de iniciativas que, no interior do próprio sistema, fluem de situaçóes e contradiçóes anteriores e prepa- 
ram o terreno para novas recorrências. Descarta-se a auto-suficiência das condições que envolvem a gestão pública e as reaçóes corretivas que automaticamente a reconduzem à estabilidade.

\section{Gestão pública e desenvolvimento}

"A economia vai bem, mas o povo vai mal," dizia-se no tempo da ditadura militar. Hoje, quem vai indo bem é o setor privado, garantindo o desempenho positivo da economia, afirma-se. Por sua vez, ineficiente, o Estado já não faz sua parte, está falido e desenganado devido à uma estrutura administrativa irracional e redundante. O problema, dizem os peritos e os meios de comunicação, é que a máquina estatal cresceu sem critério. Tanto, que o principal desafio a partir de agora é "definir politicamente os objetivos do Estado - seu tamanho, o grau preciso de sua intervenção na sociedade - e reestruturá-lo de maneira a torná-lo tão eficiente quanto as empresas que atuam a contento no setor privado" (1).

Em 1992, o vice-presidente do Banco Mundial para a América Latina e o Caribe arriscava dizer que o crescimento do produto interno brasileiro era devido a um "setor privado forte e dinâmico", em nada condizente com o "atraso". que marca as instituiçóes públicas do país (2). Sem embargo, no ano seguinte revelou-se que mesmo durante a década perdida o setor público destacou-se muito mais que a iniciativa particular. A própria Fiesp - Federação das Indústrias do Estado de São Paulo - selecionou doze pontos positivos da economia brasileira nos anos oitenta e constatou que a ação estatal continuava a sobressair (3), através da administração direta ou indireta, de parcerias ou mesmo por obra de incentivos, subsídios e políticas voltadas ao incremento do comércio exterior.

E não foi só a economia. Não obstante opiniōes levianas sobre as políticas públicas no Brasil configurarem um Estado de mal-estar social, do ponto de vista do desenvolvimento social, o saldo da intervenção estatal também foi positivo. Durante a década passada os resultados obtidos a partir da aplicação de indicadores de saúde, educação e renda, mostram que todos os estados brasileiros "melhoraram o seu desempenho na área social" (Rodrigues, 1994a). Com efeito, o último relatório do Pnud (1994:105) mostrou que o desenvolvimento bumano (calculado em termos de longevidade, conhecimento e padrão de vida) no Brasil há tempos está a ponto de igualar-se às naçóes mais avançadas. Feito apreciável, se levarmos em conta que trinta anos atrás os índices do país eram tão baixos quanto os das nações mais atrasadas e que nos anos setenta ele já fazia parte do grupo dos países com grau médio de desempenho.

No mesmo período, outros países (Coréia do Sul, Portugal, Panamá e Colômbia) fizeram ainda melhor e, de 1960 a 1982, mais de uma dezena de nações emergentes (incluindo o Brasil) obteve taxas de investimento superiores às dos 
Estados Unidos nas primeiras seis décadas deste século. Ainda em termos comparativos, "sem intervenção estatal a acumulação de capital na Inglaterra durante a Primeira Revolução Industrial foi cerca de um terço da taxa obtida pelos países em desenvolvimento; a taxa de poupança dos ingleses não chegou à metade" (Lewis \& Williamson, 1988:29).

Em outros aspectos crescemos também. O desemprego é sempre um produto inevitável do vertiginoso desenvolvimento econômico, que inflaciona também a taxa de crescimento natural da população. Quando a relação terra/trabalho é favorável, lavra-se e cultiva-se mais. Quando não, os agricultores imigram. No final do século passado o crescimento demográfico urbano devido ao êxodo rural nos Estados Unidos e na Austrália foi de 3,5\%. Nas décadas de sessenta e setenta algumas cidades do Terceiro Mundo cresceram $6 \%$ por ano, tanto que "não existe infra-estrutura que agüente. Tudo fica faltando: escola, transporte, água encanada, energia elétrica etc. A única coisa que se pode dizer a favor da excessiva urbanização é que ela tende a diminuir a taxa de natalidade" (Lewis \& Williamson, 1988:17).

A existência de infra-estrutura é precisamente um fator essencial de crescimento, humano e econômico. Investimento em infra-estrutura não surte efeito imediato sobre a produção, porém estoques elevados de infra "permitem que o crescimento se mantenha por períodos mais longos" (Ingram, 1994:12), o que seguramente contribuiu para manter a trajetória factível do crescimento do Brasil durante a década passada, em particular no caso dos serviços públicos.

No entanto, a externalidade temporal da infra-estrutura tende a dissolver-se no quadro permanente de elasticidade de oferta de mão-de-obra desqualificada. Nosso desempenho educacional (a média de anos de escolaridade do brasileiro quatro - é similar à da África do Sul, com a diferença de que a nossa é mais baixa do que todos os demais países das Américas) explica-se através do número de pessoas que, no Brasil, vivem em situação de pobreza absoluta (inferior apenas a China, Índia e Bangladesh). De modo geral, os níveis de educação tendem a subir apenas quando a renda é maior e melhor distribuída ou o padrão dos serviços públicos é elevado, ou ambos (Higgins, 1968:21).

\section{Dívida e desequilíbrio}

O discurso que considera o Estado algo parecido ao contexto do pecado de Jean-Luc Godard e nele localiza o âmago da crise tem suas armadilhas, não é um mero nonsense. Expressa perplexidade diante do inexorável avanço da modernização, a desregulamentação sem peias que favorece uma ordenação econômica supranacional sem fronteiras geográficas ou limitaçóes de políticas públicas. Com efeito, no começo dos anos setenta grandes transformações afetaram os países 
centrais: a desregulamentação do sistema monetário internacional fez-se acompanhar de estagnação dos setores-chave da economia, taxas explosivas de expansão do crédito, proliferação de ativos financeiros, declínio das taxas de investimento fixo e de um crescimento desequilibrado dos setores de serviços (Wachtel, 1986; Scuro Neto, 1989b:118).

O Brasil não sentiu logo no início todos os efeitos dessa transição. Todavia, o impacto de uma de suas resultantes, a dívida externa (4), foi suficiente para acentuar, no final da década, o desequilíbrio entre o setor público e o setor privado, em particular quando as empresas foram autorizadas a quitar antecipadamente junto ao Banco Central suas obrigações com os credores estrangeiros. A prinć́pio a estatização do endividamento privado não se apresentou como sendo um negócio absolutamente ruim para o governo, de vez que os encargos com transferências permaneciam constantes e os juros relativamente baixos.

Subitamente, porém, as despesas financeiras começaram a crescer (de 2,7 para 11,4 bilhōes de dólares, no período de 1978 a 1982). Descontrolada, a dívida pública acelerou a inflação, reduziu o ritmo da economia, debilitou o planejamento estatal. A arrecadaçáo despencou e a carga tributária diminuiu com o aumento dos incentivos fiscais à exportação, a desaceleração da economia, a sonegação, os vários planos de estabilização (que aumentaram as distorções do sistema tributário e estimularam a evasão fiscal), a diminuiçáo da base de tributação, e a própria Constituição de 1988, que transferiu recursos aos estados e municípios sem, contudo, definir a competência das três esferas de governo.

Nesse meio tempo, ao abrigo da desvalorização cambial e das altas taxas de juros no mercado internacional, o setor privado ia se ajustando com medidas de restruturação defensiva (demissōes, arrocho, repasse de custos, sobretrabalho etc.), enquanto o setor público acumulava disfunções. Com efeito, dos 2,7 milhóes de empregos criados no mercado formal de trabalho, entre 1980 e 1988, cerca de $60 \%$ foram oferecidos pela administração pública: na esfera federal, de 1984 a 1988 , o emprego cresceu $198 \%$ no judiciário, $132 \%$ no legislativo e $108 \%$ no executivo. Nos estados e municípios, entre 1982 e 1985, foram criados respectivamente 2,5 e 6 vezes mais empregos que no governo federal (5).

No final da década, o desequilíbrio entre o setor público e o privado era tão acentuado que as pessoas físicas e as empresas estavam em situação de liquidez; muitas delas haviam-se tornado credoras do Estado. Mesmo assim, a demanda por serviços públicos continuava aumentando, não apenas devido ao crescimento demográfico urbano, mas também pelo "aumento qualitativo que todos exigimos do setor público" (Staub, 1989). Esse aumento reflete não só a pressão dos taxpayers que exigem do setor público mais eficiência e qualidade - face ao abandono de certas funçóes que o setor privado não pode ou não quer assumir -, bem 
como repercutia no seio das amplas faixas de contribuintes que, por um tempo, tiveram acesso à cobertura privada, porém de algum modo a perderam e voltaram a depender da rede pública.

Tais exigências, acrescidas das demandas de quase $\mathbf{1 0 0}$ milhões de pobres $\mathrm{e}$ carentes, já não podiam ser atendidas porque a capacidade de captar poupança externa havia-se esgotado e porque diminuíra de forma substancial a carga tributária líquida. Daí a peculiar situação na qual, de um lado, fazia-se necessário uma administração pública eficiente e moderna (a ponto de satisfazer a casa-grande, os cidadãos que requerem atenção personalizada, ao estilo do Primeiro Mundo) e, de outro, resgatar o conceito de servidor público, para ao mesmo tempo atender a senzala, a massa permanentemente envolvida com a própria sobrevivência (6).

\section{A esfinge e a democracia}

No dicionário, eficiência e eficácia significam a mesma coisa: capacidade de produzir resultados. Na prática, todavia, para ser eficiente é preciso produzir resultados com um mínimo de recursos, condição fundamental para resistir à concorrência. Por seu turno, eficácia quer dizer capacidade de reproduzir nos escalóes inferiores as ordens emanadas do topo da pirâmide (7). Nesse sentido, eficácia é algo mais que eficiência, assemelhado ao comandamento dos manuais das escolas militares e à governabilidade do vocabulário político.

O déficit de governabilidade é precisamente um dos maiores problemas da gestão do setor público brasileiro, no qual, nas palavras de um ex-Secretário da Administração de São Paulo, "um comando político eleito democraticamente pela população tem dificuldades de governar, em função de estruturas ... constituídas, de interesses políticos ... diversos, interiores às vezes à própria máquina estatal e portanto nem sempre condizentes com o interesse global da sociedade." Por isso, segundo ele, na "democracia brasileira não é possível governar": a "estrutura coloca em risco" o próprio processo democrático (Goldman, 1989).

Mais ou menos nessa época, Fernando Henrique Cardoso afirmava: "Nós, que fizemos a redemocratização, fracassamos na arte de governar." Com efeito, governar é bem mais complicado. Não é, como a democracia liberal, irmã gêmea da economia de mercado, "um mero produto de força e matéria," um desordenado processo de seleção natural. Exige leis que a natureza não escreve, impor ordem ao caos. Talvez por conta disso governar tenha sido até aqui tão difícil para os arquitetos da redemocratização, que continuam encarando a máquina como se um monstro ela fosse. Uma esfinge espertalhona que não se atira do rochedo, onde está confortavelmente instalada, mesmo quando deciframos seus enigmas. 
Tais enigmas condicionam a maneira pela qual a máquina administrativa é percebida pela opiniáo pública. De forma singela procura-se explicar como, apesar de todas as reformas até aqui tentadas ou efetivamente implementadas, determinados interesses estrategicamente posicionados acabam sempre levando a melhor. Para isso, o raciocínio prossegue, contam com a ajuda do corporativismo dos servidores, através do qual conseguem preservar ou até mesmo ampliar as estruturas de que se apoderaram, prejudicando o funcionamento da administração pública (8). Esse ponto de vista assume que os valores, as atitudes e as crenças prevalecentes no seio da opiniáo pública refletem, em um determinado momento, verdades estabelecidas. Na realidade reproduzem táo-somente parte do processo formativo de opinião, expressam um consenso que resulta do choque de pontos de vista acerca de questóes controversas, delicadas, ainda suscetíveis à discussão.

Não obstante, a questão pode ser melhor analisada com a ajuda de um outro modelo no qual a idéia do que contribui para preservação ou desenvolvimento (função) é dissociada de grupos ou estruturas e articulada ao conceito de sistema. As condiçōes de controle, estabilidade, integraçáo e eficácia, em um contexto dinâmico, admitindo interação e intercâmbio dentro e fora do compasso do sistema passam a ser o foco principal da análise (Parsons, 1951). O modelo admite uma relafão de dependência entre as condiçöes de governabilidade do setor priblico $e$ a eficácia do setor privado dada através: da influência do Estado na economia; do impacto do setor público nos mercados; da capacidade administrativa do governo; da qualidade das leis que estabelecem limites à livre iniciativa; e da característica do planejamento que baliza desempenhos e avalia resultados.

A partir da década de setenta, os processos de reforma do Estado passaram a representar o cliente como sendo paradigma das relações sociais e a estratégia empresarial como a única norma válida, inclusive para a gestão pública. Ao mesmo tempo, um poderoso movimento político de inspiração conservadora abalava as concepçóes de governo e forçava o reexame das formas pelas quais o setor público desempenha sua missāo. Os governos de Canadá, Estados Unidos, Japão, Holanda, Nova Zelândia, Grã-Bretanha (e o Chile, na América Latina) chegaram a propor uma nova divisão de trabalho com o setor privado. A intençáo era sanear as finanças do Estado e promover uma gestão pública eficaz através da privatização de empresas estatais e serviços públicos.

Por seu turno, sem desmentir as tendências que se impunham com grande rapidez, porém recusando-se a questionar o papel e a missão histórica do Estado, a maior parte dos governos optou por uma soluçáo de compromisso: a reforma administrativa. A proposta era obrigar o setor público a desvendar as condições do próprio funcionamento, as circunstâncias que envolvem gastos públicos, qualidade dos serviços e utilização do dinheiro dos contribuintes, tendo em vista 
aumentar a eficiência da máquina e a eficácia das políticas macroeconômicas (9).

A reforma evoluiu desse modo dando destaque ao conceito de sistema: as virtudes essenciais do Estado e do serviço público foram preservadas, mas na perspectiva do amadurecimento das relaçốes com o setor privado. O que exige, ademais, maior critério na importação de medidas aplicadas pelas empresas particulares na correção das práticas inoperantes do setor público, as quais, muitas vezes, limitam-se a remanejamentos e modificaçóes superficiais envolvendo custos consideráveis, inclusive do ponto de vista político (10).

Dessa forma, desde 1989 têm-se evitado estatizar ou privatizar em grande escala. A alternativa foi promover condições de maior governabilidade, políticas de saneamento financeiro, controle de despesas e harmonização entre a eficiência administrativa do setor público e a política macroeconômica (Ocde, 1990). Dentre as iniciativas tomadas destacam-se:

- sintonizar um setor público eficaz e eficiente com um desempenho cada vez melhor do conjunto da economia;

- melhorar a qualidade para satisfazer os clientes dos serviços públicos;

- dar um caráter quase comercial às atividades do Estado, concentrando-se em resultados e gestão financeira;

- gerir recursos humanos de forma integrada e estratégica, simplificando e flexibilizando os quadros do funcionalismo;

- encarar a informática como o fulcro da modernização (e da renovação dos quadros) do serviço público;

- articular os processos do Executivo e Legislativo na regulamentação de normas administrativas, redefinindo áreas e formas de cooperação entre os dois poderes;

- acompanhar os processos de reforma e as modalidades de obtenção de resultados.

\section{Governo e processos supranacionais}

Da perspectiva global, todavia, a reforma administrativa não possui um tratamento homogêneo. Os países industrializados a promovem levando em conta o elenco de medidas aqui mencionado. À periferia ainda estão reservadas receitas condicionadas por violentos ajustes de preços, relaxamento de restriçóes às importações, desregulamentação generalizada e indiscriminada, privatização em larga escala. Em outras palavras, enquanto, para manter o bom funcionamento da economia e a sociedade integrada, na casa-grande busca-se equilibrar os mecanismos de mercado e as instituiçóes que ficam fora de seus domínios, na senzala continuam a ser articulados esforços com apoio internacional para tornar o mercado um Radamés, o condottiere supremo. 
A mesma postura reproduz-se através da omissão da opinião pública, que parece aguardar a soluçáo dos problemas do Estado por um processo de destruição criativa, no qual funcionalismo e setor público morrem de morte natural. Reproduz-se, ademais, graças à falta de determinação política diante da crise motivada provavelmente não por má administração do setor público, mas por processos de natureza supranacional, cujas regras transcenderiam os países e o próprio Estado tomado como entidade autônoma, bem-gerenciada ou não (11).

Na linha desse argumento autoridades, como o economista Jan Tinbergen (Pnud, 1994:82-89), encaram com otimismo o surgimento de formas globais de governo, como um Banco Central Mundial, uma instituição internacional antimonopólio e uma organização mundial do comércio (acordos multilaterais envolvendo produtos, capitais e trabalho), na tradiçāo da Carta de Havana de 1948. Com isso (e mais um organismo reservado à sociedade civil global), pretende-se obter uma gestáo macroeconômica mais saudável que a dos governos nacionais. O FMI, por exemplo, seria recriado segundo o projeto original de Lorde Keynes: um banco para fornecer linhas incondicionais de crédito, em lugar de apenas controlar rigidamente países devedores e nossas idiossincrasias culturais em matéria de administração pública.

Nesse sentido, ao demonstrar como o FMI e suas propostas foram irrelevantes no contexto econômico brasileiro (12), não teria a reforma monetária chamada Plano Real mostrado o caminho também para a reforma administrativa, no bojo de um projeto nacional reunindo governo, setor privado e sociedade civil na recuperação da capacidade estatal de investir e planejar, assim como mediar conflitos (Ferraz 1991; Fenap-Enap, 1994)? Mas, qual seria o efetivo impacto do projeto e de uma tal agregação de esforços e apoios políticos diante da resistência dos interesses entrincheirados na sociedade civil organizada e no setor público? Por quanto tempo e até que ponto poderia um pacto dessa natureza por melhor sustentado e representativo que fosse - substituir os atuais mecanismos da organização política da sociedade e compensar a estabilidade que os mesmos produzem quando amortecem conflitos, evitam confrontaçăo direta e estabelecem um simulacro de compatibilidade entre grupos antagônicos (Merton, 1967:135)?

\section{Governo por programas}

De uns tempos para cá o governo, quando nãó procura cuidar de si mesmo e da própria sobrevivência, empreende iniciativas de caráter emergencial, buscando resolver na prática o dilema casa-grande/senzala. Tendo em vista questóes complicadas e urgentes como drogas, fome, miséria e desemprego, desponta a noçāo de governo por programas, alternativa para compensar de algum modo a debilidade da administração direta, assimilando alguns princípios avançados de reforma ad- 
ministrativa, em particular a ênfase nos resultados das atividades e na autonomia de ação e iniciativa dos quadros operacionais (Barelli \& Troyano, 1991; Alves \& Lima, 1991; Matus, 1991).

A ação do governo desenrola-se na base de objetivos estratégicos e sustentação forjada pelo medo generalizado da sociedade com relação à uma crise irreversível de governabilidade. Busca a aquiescência ou mesmo o apoio dos adversários, sem todavia precisar cooptá-los. Promove consenso, com a ajuda dos meios de dissuasão de que dispóe a opinião pública. Abre espaços de negociação, rompe barreiras ao diálogo, fomenta alianças, incentiva a formação de variedade genética dentro do governo e cria alternativas para seus próprios objetivos, incorporando alterações de conjuntura.

Sempre tomando iniciativa o governo busca novos patamares de eficácia, mesmo porque não bastam a legitimidade das urnas, projeto político ou apoio suficiente para exercer um mandato a contento só nos meses iniciais ou no primeiro ano. Com efeito, os governos democráticos parecem cada vez mais encerrar seus mandatos, "com baixa governabilidade, em açóes rotineiras, cedendo espaço para a oposição que retomará o mesmo ciclo de empolgação inicial, frustração e descrédito final” (Barelli \& Troyano, 1991:19).

Por seu turno, da mesma forma que as estratégias há algum tempo concebidas por especialistas em administração empresarial e militares (Scuro Neto, 1986), o governo por programas não setoriza a realidade nem se deixa orientar por açóes exclusivamente econômicas, técnicas ou administrativas. A prioridade passa a ser a eliminação da "carga negativa", de problemas que podem ser descritos "em toda sua complexidade" por indicadores ou vetores que "atestam qualitativa e quantitativamente as condiçóes negativas que se pretende enfrentar" (Barelli \& Troyano, 1991:21)

Para traduzir objetivos em termos de resultados esse governo perda zero não fica preso a regulamentaçóes detalhadas. Concentra-se nos desvios de rendimento avaliados a partir da atuação de quadros operacionais, aos quais é concedida ampla autonomia e iniciativa. O gerenciamento das operaçóes, com orçamento e recursos definidos, permite delegação de responsabilidade e poderes, cobrança de resultados e conhecimento dos motivos de desvios ocorridos.

No governo Itamar Franco, os defensores mais articulados dessa concepção obtiveram apoio e recursos para verificar na prática suas idéias. No Ministério do Trabalho, Walter Barelli (1993) lançou o Programa de Reciclagem Profissional, para sintonizar seguro-desemprego, recolocação no mercado de trabalho e preparação profissional do trabalhador, no objetivo de "reduzir o risco de nova dispensa motivada por falta de qualificação". 
A estrutura do Sistema Nacional de Emprego foi reativada de acordo com a convenção da Organização Internacional do Trabalho de 1948, obrigando o Estado a manter serviços públicos e gratuitos para organizar da melhor forma possível o mercado de trabalho, intervindo na contratação e colocação da mãode-obra. Adaptando tais disposições às condições recessivas do quadro econômico, o programa buscou dirigir a atenção das instituiçōes de formação profissional para o problema dos desempregados.

Ambicioso e assaz abrangente, o programa visava a dar ao trabalhador um novo perfil profissional que, "além de habilidades específicas para uma determinada ocupação" incluía o domínio de competências básicas (comunicação e expressáo, cálculo, raciocínio lógico, criatividade, capacidade decisória, habilidade de identificar e solucionar problemas, capacidade de propor e incorporar inovações etc.), bem como "informações culturais e de cidadania que facilitam a integração do indivíduo na sociedade e no trabalho" (Barelli, 1993).

No entanto, deixando-se envolver na atmosfera de entusiasmo messiânico gerada por um outro programa, de combate a fome e à miséria, o projeto acabou assumindo premissas equivocadas ao imaginar que o problema é a geração de empregos, quando, na realidade, os obstáculos ao desenvolvimento do mercado de trabalho no Brasil dizem respeito ao alto grau de informalidade do emprego e à taxa de precariedade ampla do trabalho (relativa à redução do poder de compra do salário mínimo) (13). Barelli sabia disso e resolveu lutar pelo registro em carteira de todos os trabalhadores, elevação do valor em dólar do salário mínimo e fortalecimento da negociação coletiva (através de acordos a médio termo) na formação de preços e renda. No entanto, prejudicado por excessiva abrangência de objetivos, não soube articular a multiplicidade de todas as frentes abertas no contexto do programa original.

\section{Desemprego de risco}

O programa que Barelli e seus colaboradores apresentaram constitui certamente uma das iniciativas em harmonia com o refluxo do atual ciclo da crise da gestão pública, de acordo com situaçóes e contradiçóes anteriores, essencialmente internas ao sistema, corrigindo e preparando o terreno para novas recorrências. Mas precisa mudar de ênfase, ser menos abrangente.

Em lugar de um esquema gigantesco que atende indiscriminadamente várias categorias de desempregados, deve-se ter programas-piloto de caráter experimental voltados à redução do desemprego a longo termo que vitima trabalhadores definitivamente demitidos ou há muito tempo sem serviço. Com isso evita-se também o insucesso motivado pelos incertos resultados de uma estrutura devoradora de recursos, divorciada da administração direta (14), em grande parte dedicada simplesmente a repassar fundos públicos a particulares. 
Seguidos períodos recessivos nos últimos dez anos obrigaram muitos trabalhadores a amargar uma situação de permanente desemprego. Perderam as aptidões que possuíam e a motivação para continuar procurando o que fazer. As empresas não querem contratá-los. Já não têm direito ao seguro e irão compor o núcleo mais complicado e sem esperança da cadeia do desemprego, gerando para si, suas famílias e para a sociedade problemas ainda mais graves que o próprio desemprego.

Por outro lado, uma forma de encaminhar essa questão, tal como atestam no exterior sistemas com mais de três décadas de experiência, é o profiling, a identificação antecipada do trabalhador mais arriscado ao desemprego de longo termo e propenso a encontrar maiores dificuldades no mercado e com chances extras de esgotar seu seguro-desemprego antes de conseguir nova ocupação. Uma vez identificado esse trabalhador adentra um segundo estágio, de assistência intensiva na busca de emprego e efetiva preparação para uma nova ocupação: workshops sobre técnicas na procura de emprego, avaliação individualizada, aconselhamento e encaminhamento. Em determinados casos as empresas também ajudam, uma vez que o programa adquire caráter mais profissional, distanciado das açôes da cidadania, da ênfase caritativa e da ocupação precária.

O seguro-desemprego, por seu turno, deixa de ser um benefício passivo, fonte de renda provisória que em nada ajuda na obtenção de um novo emprego. Via profiling, o seguro evolui à condição de instrumento para uma ativa intervenção no mercado de trabalho. A educação e o treinamento profissional intercedidos pelo sistema tornam-se mais seletivos, pois restringem-se aos trabalhadores que precisam de novas ou melhores aptidóes para conseguir emprego. Por sua vez, aos menos ajustados e necessitados de formação a longo prazo, pode-se oferecer bolsa de estudos ou auxílio complementar ao seguro-desemprego.

O problema é que o profiling parece coisa de Primeiro Mundo, diante da elasticidade da oferta de mão-de-obra desqualificada no Brasil. Nesse caso a solução pode estar na instituição de esquemas de crédito para aumentar ( $\mathrm{em}$ média $20 \%$, às vezes dobrar) o rendimento dos pobres que, muitas vezes, conhecem boas oportunidades de auferir renda, mas não têm recursos para investimentos proveitosos. Falta-lhes acesso ao crédito.

Segundo o Pnud (1994:40), os pobres hoje em dia são "credores de muita confiança e por isso representam um risco muito bom". Nas operaçōes de empréstimo aos pobres "taxas de reembolso de $\mathbf{9 0 \%}$ ou mais são cada vez mais freqüentes". Além disso, "os pobres são capazes e estão dispostos a pagar taxas de juros de mercado". Na verdade, devido à sua condição de pobreza muitas vezes acabam pagando juros extorsivos. 
Empréstimos pequenos, todavia, são mais complicados e têm custo administrativo maior que as grandes somas. A alternativa seria emprestar a grupos congêneres, uniformizar os termos dos empréstimos, simplificar procedimentos bancários convencionais, orientar pessoas e comunidades com relação a investimentos, subsidiar bancos que atendem o maior número possível de pobres tomadores de empréstimo etc.

Ter crédito faz diferença, para os pobres ainda mais. $\mathrm{Na}$ Índia, $64 \%$ dos beneficiados aumentaram sua renda anual em mais de $50 \%$; em $71 \%$ dos casos, o dinheiro emprestado permaneceu investido por dois anos. Nas Filipinas, quem pediu emprestado tinha em média 5,7 dependentes e as mulheres receberam $80 \%$ dos recursos. Na República Dominicana, a taxa de geração de emprego de quem conseguiu um empréstimo foi 20 vezes maior. $\mathrm{Na}$ Costa Rica, criou-se um novo emprego para cada mil dólares emprestados e a média do aumento da renda de 450 pequenos empréstimos foi superior a $100 \%$ ao ano.

\section{Sumário e conclusões}

Apesar de conservador, o sociólogo Peter Berger não vacila quando diz que a sociologia é uma ciência "autenticamente subversiva," cuja marca principal sempre foi o "espírito revelador" que "desmascara interesses ocultos encobertos pela ostentação da retórica." Neste ensaio, porém, não procuramos desvelar interesses; preferimos destacar as questóes toldadas pela bruma que envolve o discurso sobre a crise do Estado. Fiéis à nossa missão subversiva procuramos concentrar o argumento em algumas opiniốes correntes, difíceis de contestar porque são defendidas por órgãos e atores íntegros e bem informados, capazes de expressar de forma legítima o sentimento da sociedade.

Esse obstáculo é contornado quando se observam elementos não-racionais ou algum tipo de manipulação no processo formador de opinião. $O$ critério que adotamos foi diferente: procuramos no processo pedaços de discurso, dados estatísticos e questôes que, por razóes de prioridade ou mesmo obsessão com relação ao tema, a opinião pública não discutiu ou deixou em segundo plano. De tal maneira que o endividamento do Estado e a complexidade da demanda dos serviços públicos acabam eclipsados por argumentos que culpam a burocracia irracional que cresce sem critério.

Essa acusação não é nova, sempre acompanhou a máquina (uma noção que designa homens passivos), principalmente em períodos de regime democrático, quando é utilizada de acordo com o spoils system na aquisição de apoio político, para garantir a lealdade de correligionários e dar continuidade ao próprio funcionamento dos partidos políticos. Outra perspectiva convencional imagina uma burocracia oficial econômica, ágil e eficaz o bastante para atender melhor a 
população e, ao mesmo tempo, formular políticas de governo, "como ocorreu nas décadas de 30 e 40 e depois, com menos intensidade, na década de 70" (15). Isto é, sob governos autoritários.

Neste artigo verificamos que a análise dos problemas da gestão pública pode, no entanto, deixar a ênfase tradicional na noção de estrutura (e grupos) e vincular-se ao conceito de sistema. Com isso a idéia de funçáo (16) pode ser tematizada em nível mais geral incorporando o caráter dinâmico, diferenciado e transformador dos processos em curso na sociedade moderna. Pode-se mostrar como a administração pública efetivamente funciona, bem como as opções abertas ao seu desenvolvimento e os problemas de caráter político e ideológico que tem de enfrentar.

Uma agenda tentativa para a reformulação da gestão pública nesses termos diz respeito a quatro tipos de problemas: à solução de problemas técnicos relativos a meios, objetivos e à coordenação de atividades com vistas a capacitar o sistema a atingir suas metas (ou seja, sanear as finanças públicas e promover uma administração eficaz, tal como definimos); empenhar-se não apenas na autopreservação da burocracia e seus dependentes, mas na ativa e consentida intervenção na sociedade, visando adquirir recursos com valor generalizado e utilidade em vários contextos; estabelecer um nível superior de integração, solidariedade ou coesão entre as unidades do próprio sistema; e reconciliar, através de um novo tipo de relacionamento, as normas e demandas da gestão pública com as do conjunto da sociedade.

Em particular, essa análise permite acentuar, de um lado, a questão da demanda, a relação entre os serviços que o Estado pode oferecer e os usuários estão dispostos a comprar. Um problema que o modelo do cliente resolve a seu modo, restabelecendo plenamente as funçóes de mercado e equacionado demanda e oferta através do mecanismo de preços (17). Considerada na sua complexidade, todavia, a questão abriga distorçôes devidas ao atendimento indiscriminado (beneficiando quem precisa menos), responsabilidades não fixadas, critérios estabelecidos de forma burocrática, recursos absorvidos em grande parte pela própria estrutura de atendimento, desvios de função etc.

Por outro lado, a partir de uma perspectiva de mudança e de acordo com a opção que o país parece estar fazendo ao romper seu prosaico isolamento (18) ao aceitar a moderna sociedade industrial como o sistema social mais completo e acabado (justamente porque funcionalmente é o mais diferenciado), o desenvolvimento da gestão pública brasileira não poderá mais deixar de lado as tendências globais e as experiências levadas a cabo no exterior.

Essa integração realiza-se na base de problemas concretos e situações pro- 
postas no contexto nacional, porém toma como parâmetro os países mais desenvolvidos, na sua acepção mais típica, livre "de qualquer influência perturbadora" (Marx, 1974). Desse modo, tendências mundiais reproduzem-se nas formas e movimentos da sociedade nacional, mas não ensejam a formação de nenhum novo sistema implicando em desuso do outro. Tal sistema, animado por um movimento peculiar, reuniria todas as naçóes sob a égide de uma sociedade global constituída como "uma realidade original, desconhecida, carente de interpretaçóes" (19). Entidade "além das sociedades nacionais," ela seria dotada de "vida e dinâmića estrutural próprias," a partir das quais configurar-se-ia uma nova "ciência" chamada "globologia," "análoga à sociologia" e voltada aos estudos de estruturas e processos do world system como um todo" (Bergesen, 1982).

Na verdade, portadores de cartóes de crédito, a revista The Economist, a rede CNN, os bolsões de modernidade e os espaços globalizados não configuram uma singular sociedade mundial, que nada é além de uma simples metáfora. Como arrisca Milton Santos, "todos os.lugares são mundiais, mas não há um espaço mundial. Quem se globaliza, mesmo, são as pessoas e os lugares". Mais especificamente, aqueles elementos são funçóes do tempo e do espaço em que ocorrem (20). Ou, para lembrar a definição de Leibniz, são variáveis consideradas em relação a uma ou outras tantas em termos das quais podem ser expressas de acordo com o valor de que seu próprio valor depende.

\section{Notas}

1 Folba de S. Paulo, 11 set.1994. Nos meios acadêmicos afirma-se sem hesitação que "o desafio da política social consiste, precisamente, em conseguir incorporar às iniciativas públicas o dinamismo que caracteriza a concepção estratégica vigente nos serviços privados" (Tedesco, 1989).

\section{Gazeta Mercantil, 24 set.1994.}

3 Os doze pontos positivos da economia brasileira nos anos oitenta:

- a rede rodoviária cresceu 47 mil quilômetros;

- a proporção de residências com água encanada passou de 66 para $72 \%$;

- a coleta de lixo residencial, que atendia apenas $54 \%$ das casas no começo da década passa$\mathrm{da}$, hoje atinge $62 \%$ delas;

- a mortalidade infantil caiu de 71 para 56 em cada mil crianças;

- o brasileiro vivia em média 62 anos no início da década, e hoje vive 66;

- o número de passageiros no transporte aéreo cresceu $5,8 \%$;

- a tonelada/quilómetro de carga aerotransportada subiu $29 \%$;

- a população economicamente ativa cresceu $3,5 \%$ ao ano;

- os serviços aumentaram $3,2 \%$ ao ano e hoje perfazem $52 \%$ do PIB;

- as exportações de manufaturados cresceram $4 \%$ ao ano e de US\$27 bilhões para US\$39 bilhôes;

- a participaçáo dos manufaturados na pauta de exportaçóes subiu de 57 para 61\%;

- o governo começou a abrir o mercado interno e as importações cresceram $7 \%$ ao ano $(O$ Estado de S. Paulo, 11 ago. 1994). 
4 Até recentemente, a própria política econômica era implementada sem atinar para as transformaçōes no plano mundial e, por isso mesmo, era incapaz de atacar as causas primárias desse impacto: "tal incapacidade decorreu, ora por não se considerar, juntamente com o caráter inercial da inflação, o desequilíbrio fiscal como elemento central no processo de aceleração de preços, ora por ser politicamente inviável empreender as reformas necessárias para sustentar os bons resultados iniciais" (GAC, 1994:28).

5 Mesmo crescendo menos que a população, o nível de ocupação no emprego no setor público atuou como "um verdadeiro fundo de seguro-desemprego" (Chahad, 1991:59-63). O governo, porém, não deixou de aplicar a seu modo a restruturaçăo defensiva vitimando o funcionalismo da administraçáo direta (entre 1991 e 1992 as despesas federais com pessoal e encargos em relação à receita corrente passaram de 41,4 para $12,4 \%$, enquanto as despesas de capital saltavam de 13,6 para $71 \%$ ) e promovendo uma concentraçáo de renda maior que a do setor privado.

6 Mesmo do ponto de vista metodológico parece difícil determinar as prioridades das políticas públicas: Rodrigues (1994b) alega que o HDI, índice do PNUD para o desenvolvimento humano, gravita em torno de uma preocupação compreensível apenas para indivíduos que superaram os problemas materiais da sobrevivência (o grau de satisfação pessoal) e não a partir da justica social, dos resultados sociais do desenvolvimento econômico.

7 Por sua vez, as grandes empresas, estatais ou privadas, historicamente têm procurado desestimular a competição, aumentando custos e diminuindo as chances de sucesso das demais. Seu objetivo năo é tanto eficiência quanto ser eficaz, ou seja, constituírem-se em organizações poderosas.

8 Folba de S. Paulo, 11 set. 1994.

9 Também no Brasil o governo federal começa a preparar, para as grandes empresas estatais que devem escapar à privatização, um sistema de controle com autonomia condicionada a contratos de gestâo comprometidos com as diretrizes macroeconômicas (Gazeta Mercantil, 14 out. 1994).

0 Conceitos difundidos são enxugamento, restruturafăa e reěngenharia, típicos da anorexia corporativa que determinadas organizações econômicas desenvolvem para se tornar mais esbeltas, porém não necessariamente saudáveis e eficientes. Nesse particular veja-se o mais recente livro dos professores Gary Hamel \& C. K. Prahalad, Competing for the future.

1 De acordo com esse ponto de vista, a crise é devida à desregulamentação do sistema monetário mundial (no começo dos anos setenta o governo Nixon decretou o fim da convertibilidade do dólar em ouro). No final da década ela ficou evidenciada pela relação entre o endividamento dos países do Terceiro Mundo (400 bilhōes), o crescimento do volume dos eurodólares (425 bilhōes) e o excedente na conta dos países produtores de petróleo ( 350 bilhōes). Ao mesmo tempo (precisamente entre 1970 e 1975), subiam $36 \%$ os lucros das transaçōes internacionais dos bancos (caíram, porém, $9 \%$ nos Estados Unidos) e disparavam os preços ao consumidor (134\% nos EUA e 187\% na Comunidade Européia, de 1973 a 1984).

(2 Veja-se Ibrahim Eris \& Luís Paulo Rosenberg, FMI: ame-o ou deixe-o; e Jeffrey Sachs, Um novo papel para o FMI e Banco Mundial (Gazeta Mercantil, 7 out. 1994).

[3 O salário mínimo deveria ser determinado pela eficiência com a qual são produzidas as mercadorias que os trabalhadores consomem para garantir a reprodução da força de trabalho no presente e nas geraçóes futuras. Contudo, hoje ele tem pouca relevância na estrutura salarial brasileira, em parte devido ao decrescimento de seu valor, "decorrente das políticas de recomposição parcial adotadas no período 1989-93" (Seade, 1994). 
14 Neste particular, a Convenção 88 estabelece que o serviço de emprego é de caráter permanente e deve ser provido de funcionários estatutários.

15 Jomal do Brasil, (Rio de Janeiro, 7 nov. 1994). O tipo ideal de burocracia, segundo esse modo de ver, é o Itamaraty, que, no entanto, presta serviços de natureza e qualidade tão indefinidas quanto suas próprias formulaçóes de política externa. Muitas vezes as ilhas de referência do funcionalismo estão superpovoadas por nativos virtualmente improdutivos, faux frais, fardos necessários, componentes estratégicos de um capital humano overqualified.

$16 \mathrm{O}$ termo função refere-se às "várias soluçóes para um determinado complexo de problemas que um sistema pode adotar para sobreviver", tomando "sobreviver" em relaçáo a persistência, evolução e transformação (Rocher, 1974:155).

17 Affonso Celso Pastore, no jornal Zero Hora (Porto Alegre, 25 set. 1994). Na Nova Zelândia e Austrália, por exemplo, o governo permite que a iniciativa privada preste serviços públicos e concorra com órgãos desligados da administração direta, conforme regras quase comerciais e avaliação de resultados em função do rendimento do capital investido.

18 Os brasileiros parecem achar que o fluxo internacional de idéias e experiências pode servir para qualquer coisa, menos ser um fator de transformação ou chave para destrancar nossos rígidos mecanismos domésticos. Nas palavras de Mário de Andrade, cada um de nós "realiza o Brasil segundo a própria observaçăo," razão pela qual "assuntamos, matutamos e realizamos" com o espírito abatido à sombra de um campanário da província e de uma bananeira, achando que nada lá fora é com a gente, a não ser por uma "simples coincidência de objetivos" (Scuró Neto, 1993:124).

19 Para reanimar a reflexão estruturalista em tempos de modernidade utilizam-se surrados preconceitos contra o funcionalismo, que, na qualidade de instrumento imperialista, reproduziria "as relaçóes, processos e estruturas ... que se desenvolvem em escala mundial," exclusivamente como uma "ampliaçāo" das sociedades nacionais ou grupo de países dominantes (Ianni, 1994:153). Ora, o que está em questáo é a moderna sociedade industrial, totalidade na qual, segundo um afamado funcionalista temporão, "o país mais desenvolvido industrialmente apenas mostra, aos menos avançados, a imagem de seu próprio futuro" (Marx, 1974:19).

20 A preocupação de Milton Santos e seus colaboradores (1994) reflete a ênfase na microssociologia e fenomenologia, que deu azo à produção recente de alternativas à sociologia de Parsons (Luhmann, 1984; Giddens, 1984), visando a desenvolvimentos no tempo e espaço, o saber dialético no fluxxo dos acontecimentos ou de acordo com a atitude de Garfinkel: "waiting for something to happen which promises to clarify what has gone before". Tentativas interessantes, mas ainda insuficientes para caracterizar o tempo de forma diferente como Durkheim o fez: algo cada vez mais abstrato e emancipado das particularidades locais, parecido a um conceito matemático que esconde a própria história por detrás de sua aparente natureza lógica (Elchardus, 1988:42).

\section{Referências bibliográficas}

ALVES, Edgar Luiz G. \&ABREU, Mozart de A. e L. Crise e planejamento estratégico situacional. São Paulo, SEADE, São Paulo em Perspectiva, v. 5, n. 4, p. 23-27, 1991.

ANDERSON, Perry. As antinomias de Antonio Gramsci. São Paulo, Jorues, Săo Paulo, 1986.

BARELLI, Walter e TROYANO, Annez A. Planejar como arte de governo. Săo Paulo, SEADE, Säo Paulo em Perspectiva, v. 5, n. 4, p. 18-22, 1991. 
BARELLI, Walter. Programa de reciclagem profissional. Brasília, Ministério do Trabalho, Secretaria de Formação e Desenvolvimento Profissional, 1993 [brochura].

BERGESEN, Albert. The emerging science of the world-system. Paris, Unesco, International Social Science Journal, v. 34, n 1, p. 23-36, 1982. Citado em Ianni, 1994, p. 154-155.

CHAHAD, José Paulo Z. Emprego público e ciclo econômico no estado de São Paulo. São Paulo, SEADE, São Paulo em Perspectiva, v. 5, n. 1, pp. 59-63, 1991.

ELCHARDUS, Mark. The rediscovery of chronos: the new role of time in sociological theory. Londres, Sage, International Sociology, v. 3, n. 1, p. 35-59, 1988.

FENAP/ENAP. Políticas de ajuste e desenvolvimento social: o caso brasileiro. Rio de Janeiro, Fesp, Política e Administraf̧ẩ, v. 2, n. 1, p. 32-40, 1994.

FERRAZ, Eduardo M. de C. A crise do planejamento. São Paulo, SEADE, São Paulo em Perspectiva, v. 5, n. 4 , p. $2-4,1991$.

GAC - Grupo de Acompanhamento Conjuntural/Ipea. O periodo 1980/90: inflação sem crescimento. In: Ipea 1994, p. 27-31, 1994.

GIDDENS, Anthony. The constitution of society. Cambridge, Polity Press, 1984.

GOLDMAN, Alberto. Intervenção no seminário Estado, Administraf̧ão Pública e Gopermabilidade. São Paulo, Fundap, 1989 [mimeo].

HIGGINS, Benjamin. Economic development: problems, principles and policies. Nova Iorque, Norton, 1968.

IANNI, Octavio. Globalização: novo paradigma das ciências sociais. São Paulo, IEA-USP, Estudos Avanfados, v. 8, n. 21, p. 147-163, 1994.

INGRAM, Gregory. Sustaining infrastructure to support economic growth, contribuição ao seminário Os Desafios do Crescimento Económico, São Paulo, FGV-Fiesp, 1994 [mimeo].

IPEA. O Brasil no fim do século: desafios e propostas pära a ação governamental. Rio de Janeiro, Ipea/ Dipes, 1994.

IPEA-IBAM-ENAP. O novo pacto federativo. In: Coleção Subsidios para a Reforma do Estado, v. 1, Rio de Janeiro, Ibam, 1994.

LEWIS, W. Arthur \& WILLIAMSON, Jeffrey G. Reflections on development. In: Gustav Ranis e T. Paul Schultz (orgs.), The state of development economics: progress and perspectives. Nova Iorque, Basil Blackwell, 1988, p. 13-30.

LIPSET, Seymour M. Consenso e conflito. Lisboa, Gradiva, 1992.

LUHMANN, Niklas. Soziale systeme, Grundriss einer allgemeinen Theorie. Frankfurt, Suhrkamp, 1984.

MARX, Karl. The capital. Trad. S. Moore e E. Aveling. F. Engels (ed.). Londres, Lawrence \& Wishart, 1974.

MATUS, Carlos. O plano como aposta. São Paulo, SEADE, São Paulo em Perspectiva, v. 5, n. 4, p. $28-42,1991$. 
MERTON, Robert K. On theoretical sociology: five essays old and new. Nova Iorque, The Free Press, 1967.

MYRDAL, Gunnar. The Asian drama: an inquiry into the poverty of nations. Nova Iorque, Anchor, 1971.

OCDE. Évolutions dans la gestion publique. Paris, Ocde, 1990.

PARSONS, Talcott. The social system. Nova Iorque, The Free Press, 1951.

PNUD - Programa das Nações Unidas para o Desenvolvimento. Relatório do desenvolvimento bumano. Lisboa, Tricontinental, 1994.

POGGIESE, Héctor A. \& FRANCIONI, Maria Del C. Perspectiva e gestão conjunta: cenários de gestão conjunta e novas fronteiras entre o Estado e a sociedade. Rio de Janeiro, Fesp, Política e Administraf̧ấ, v. 2, n. 4, p. 90-97, 1994.

ROCHER, Guy. Talcott Parsons and American sociology. Trad. Barbara e Stephen Mennell. Londres, Nelson, 1974

RODRIGUES, Maria Cecília P. O desenvolvimento social nos estados brasileiros. Rio de Janeiro, Ibre/FGV, Conjuntura Económica, v. 48, n. 3, p. 52-56, 1994 a.

- O IDS e o desenvolvimento social nas grandes regióes e nos estados brasileiros. Rio de Janeiro, Ibre/FGV, 1994b [mimeo].

SANTOS, Milton. A aceleração contemporânea: tempo-mundo e espaço-mundo. In: M. Santos et alii (orgs.), Fim de século e globalizañão, São Paulo, Hucitec/Anpur, 1994, p. 15-22.

SCURO NETO, Pedro. Pactos e estabilização económica. (cap. VIII: A questão da produtividade). São Paulo, Ática, 1986.

. Labour control in postmodern society: a case study of the corporatist strategy. Ph.D. thesis, Department of Sociology, The University of Leeds, 1989a.

- Trinta anos de formaçáo econômica do Brasil. São Paulo, IAP, Nopos Rumos, v. 14, n. 14, p. 103-121, 1989b.

A rotinização do Mercosul. Brasilia, Ibri, Revista Brasileira de Política Intemacional, v. 36, n.1, p. 124-133, 1993.

SEADE. Consideraçōes sobre a importancia do salário minimo. Săo Paulo, Seade, 1994.

STAUB, Eugênio. Contribuição ao seminário Estado, Administraçấo Pública e Governabilidade. São Paulo, Fundap, 1989 [mimeo].

SCHELESINGER, Jr. Arthur M. Os ciclos da história americana. Trad. Raul de Sá Barbosa e Múcio Bezerra. Rio de Janeiro, Civilização Brasileira, 1992.

TAFNER, Paulo Sérgio \& NASCIMENTO, Hermenegildo J. L. Administraçáo pública federal: diagnóstico e linhas gerais de uma reforma. In: Ipea 1994, p. 77-86. 1994.

TEDESCO, Juan Carlos. EI desafio educativo, calidady y democracia. Buenos Aires, Grupo Editor Latinoamericano, 1989.

WACHTEL, Howard M. The money mandarins: the making of a supranational economic order. Nova Iorque, Pantheon Books, 1986. 


\title{
Resumo
}

Tentativa de dissipar a bruma que envolve o discurso sobre a crise do Estado, concentrando o raciocínio em dados, argumentos e questóes que a opiniâo pública năo quis discutir ou deixou para depois. A crise da gestão pública é encarada como sujeita a vagas de fluxo e refluxo, ou, de modo menos fugaz, obedecendo a um ciclo autogerador cujas fases derivam de condiçóes e contradiçōes passadas, dando oportunidade a novas recorrências e reaçóes corretivas de ordem automática (homeostase) provocadas por transformaçóes que se efetuam a rajadas, como as descritas. $O$ ensaio descarta abordagem convencional que segrega o setor público e apresenta o processo politico como uma configuraçáo de interesses, irrelevante hoje em dia diante da necessidade de uma reavaliaçäo afirmativa dos atuais mecanismos institucionais e procedimentos formativos de políticas públicas.

\begin{abstract}
An attempt to dissolve the heavy mist involving the discourse on the crisis of the State, through concentration on data, argument and problems which public opinion refused to discuss or left behind. The crisis of public management is seen as a movement of flux and reflux, or less fleetingly, flowing according to a self-generating cycle whose phases derive from past conditions and contradictions and further new recurrences and homeostasis, automatic corrective reactions triggered by sudden violent changes, as described here. The essay discards conventional analytical segregation of the public sector and representation of the political process as a configuration of interests, arguably irrelevant nowadays in view of the need of assessing affirmatively existing institutional mechanisms and procedures for the formation of public policy.
\end{abstract}

Pedro Scuro Neto é sociólogo, mestre em Ciências Sociais (Praga, Tchecoslováquia) e Ph.D. (Leeds, Inglaterra). Foi professor visitante nas universidades de Stanford e da Califórnia (Berkeley, EUA), assessor especial das secretarias de Relações do Trabalho e da Administração e Modernização do Serviço Público (SP). 